\title{
Study on the spatiotemporal changes and impact of reclamation areas based on remote sensing
}

\author{
Liu Jiwen ${ }^{1, *}$, Xue Linfu ${ }^{1}$, and Li Zhongtan ${ }^{1}$ \\ ${ }^{1}$ School of Earth Science, Jilin University, 2199 Jianshe Street, Chaoyang District, Changchun, Jilin Province, China
}

\begin{abstract}
Using Landsat TM and OLI multispectral image data, the accuracy of extracting sea area from different water body indices is compared. Finally, the improved normalized water body index (MNDWI) is selected to study the dynamic characteristics of the coastline and the progress of reclamation of Dalian in 1996, 2005, and 2015. The results show that: from 1996 to 2005, the area of land reclamation in Dalian reached $31.58 \mathrm{~km} 2$, and $83.55 \mathrm{~km} 2$ for $2015-2015$. It is mainly used for dock construction, industrial land, aquaculture ponds, port docks, construction sites, residents Land, commercial and financial land, etc .; from 1996 to 2015 , the total length of the coastline increased by $132.77 \mathrm{~km}$. The length of the artificial shoreline increased significantly, with its continuity in spatial distribution increased; the length of the bedrock shoreline was reduced due to the destruction of reclamation projects. Although large-scale land reclamation has brought good economic and social benefits to the local area, it also has a large impact on the marine and forest ecological environment. It is recommended to moderately develop coastal zone resources and further strengthen monitoring and supervision mechanisms.
\end{abstract}

\section{Introduction.}

Reclamation refers to the conversion of the original sea area, lake area or river bank to land, which will cause changes in marine dynamic conditions and ecological environment, and it will also cause changes in coastline and land along the coast, artificial buildings along the coas and changes of coastal ecology Conditions and marine environment. The coastline change is an important basis for studying the process of reclamation. In the past, in order to meet different scientific needs, traditional methods such as analysis of historical charts and topographic maps, surveys of in-situ coastal landforms, and surveys of shallow sea sections can be used to study coastline changes ${ }^{[1]}$. However, it is sometimes difficult to obtain relevant information and data required by these research methods, and the coastline changes with each passing day. It is difficult to quantitatively monitor the changes with conventional methods.

International research on coastline changes has begun early, with the characteristics of multidisciplinary crosscutting and diversified methods. Most of them rely on 3S technology and numerical simulation ${ }^{[2]}$. For example, Siddiqui and others use MSS and Land-sat TM images from 1978 to 1998 to extract the coastline of Karachi area in Pakistan, and the evolution of erosion and deposition of the coastline was reversed ${ }^{[3]}$. Mason et al. analyzed the coastline evolution of the Morecambe Bay in the UK based on SAR images from 1993 to $2007^{[4]}$. In 2015, Li Yaning and others analyzed the contribution of reclaimed land to expand space in China from the aspects of optimization of layout and new construction land in coastal areas ${ }^{[5]}$.

In recent years, there have been a lot of researches on coastline changes in China, but most of them are about the overall changes of China's coastline. There are few reports on in-depth research and exploration of the impact on the local ecological environment in a certain area $^{[6]}$. Therefore, this paper uses remote sensing technology to extract the dynamic changes of the coastline, which has the characteristics of multi-temporal and high resolution. Then we use GIS to analyze the area, length, and fractal dimensions of the coastline change to determine the land use types and the impact of coastline changes on the ecological environment in the study area. We also discuss the impetus of two factors, population size and rapid socioeconomic development, on land reclamation.

\section{Research area and research method}

\subsection{Regional overview}

Dalian, a tourist city with important ports, prosperous trade, developed industries, is located between $120^{\circ} 58^{\prime} \mathrm{E}$ to $123^{\circ} 31^{\prime} \mathrm{E}, 38^{\circ} 43^{\prime} \mathrm{N}$ to $40^{\circ} 10^{\prime} \mathrm{N}$ and is located in Liaoning Province, China. Dalian is surrounded by the sea on three sides, facing the Yellow Sea in the east and the Bohai Sea in the west. The total land area of Dalian is $12,574 \mathrm{~km} 2$. There are many hills and mountains in the city, and the terrain is high in the north and low in the south, and wide in the north and narrow in the south.

\footnotetext{
* Corresponding author: jiwen17@mails.jlu.edu.cn
} 
Dalian is located in the warm temperate zone of the northern hemisphere. It belongs to the continental temperate monsoon climate with a maritime climate. The average annual temperature is $10.5^{\circ} \mathrm{C}$ and the annual precipitation is about $550 \sim 950 \mathrm{~mm}$. (Figure 1)

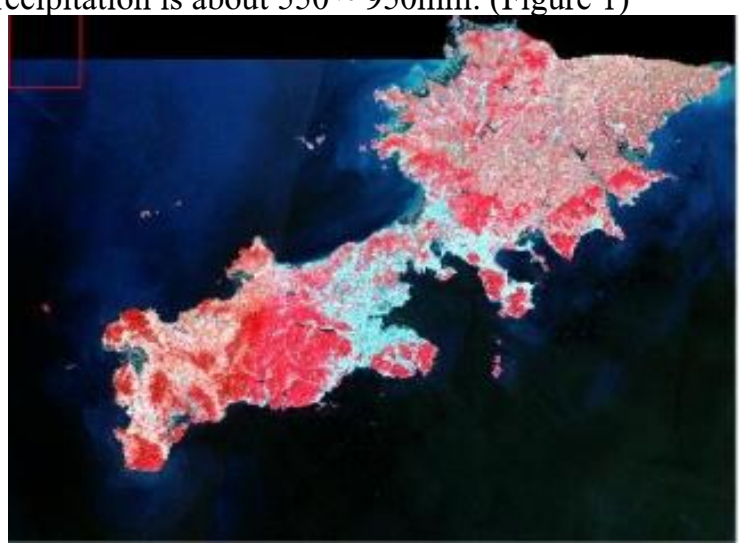

Figure 1. RGB pseudo-color synthesis of Landsat TM image of study area.

\subsection{Research methord}

\subsubsection{Remote sensing image processing}

In order to investigate the coastline changes in the study area in the past two decades, this paper uses three Landsat images of 1996, 2005, and 2015 as basis data, uses ENVI to correct each band of the remote sensing image, and corrects the gray value image to the radiance image. Correction formula $=\mathrm{DN} *$ gain + bias. Among them, gain and bias are sensor parameters. RGB pseudocolor synthesis is performed on the corrected image, and the remote sensing images of two simultaneous periods of adjacent coordinates are spliced. Finally, the image is cropped according to the coordinate range of Dalian to obtain remote sensing images in the study area. In addition, in order to explore the land use types in the coastline change area, we use ArcGIS to carry out manual visual interpretation of remote sensing images in the study area and establish related interpretation marks.

\subsubsection{Water spectral information}

According to the reflection characteristics of the feature spectral curve, the spectral reflection value of water decreases from the blue light band to the short-wave infrared band. At the short-wave infrared band, water has almost no reflection. The spectral reflection value of vegetation and soil changes from the red light band to the short-wave mid-infrared band. For the upward trend, the TM5 band is much larger than the spectral reflection value of water. Therefore, the reflectance of remote sensing spectral information of clear water can be expressed as: blue light $>$ green light $>$ red light $>$ near infrared $>$ mid infrared.

\subsubsection{Selection of water body index}

At present, the methods for extracting water area by using remote sensing images mainly include three types of single-band method, multi-band method and water body index method. This article adopts the Normalized Water Body Index (NDWI) proposed by McFeeters, the Modified Normalized Water Body Index (MNDWI) proposed by $\mathrm{Xu}$ Hanqiu based on NDWI, and Cao Ronglong's Revised Normalized Water Body Index (RNDWI) to highlight the sea area information ${ }^{[7]}$. Then, we extract the water area from the remote sensing image with the combination of the threshold segmentation.

The NDWI, MNDWI, and RNDWI selected in this paper are ratio-type indexes, and the calculation formula is as follows:

$$
\begin{aligned}
& \text { NDWI }=(\text { Green-Nir }) /(\text { Green }+ \text { Nir }) \\
& M N D W I=(\text { Green-Mir }) /(\text { Green }+ \text { Mir }) \\
& \text { RNDWI }=(\text { Mir-Red }) /(\text { Mir }+ \text { Red })
\end{aligned}
$$

In the above formula: Green is the green light band (TM2); Red is the red light band (TM3); Nir is the shortwave near-infrared band (TM4); Mir is the short-wave mid-infrared band (TM5).

\subsubsection{Extraction of sea area}

The steps for extracting the area of the sea area using the non-water body index are as follows: First, use three different water body indices to obtain the index distribution maps of the 1996, 2005, and 2015 images of the study area; The steps for extracting the area of the sea area using the non-water body index are as follows: First, use three different water body indices to obtain the index distribution maps of the 1996, 2005, and 2015 images of the study area; Then, select appropriate thresholds based on the spectrum and image gray information to classify and extract the sea area information in the image. The threshold selection principle is based on masking non-aqueous body information to the greatest extent, describing water area information as thoroughly as possible, and highlighting water area boundaries.

\section{Results and analysis}

\subsection{Comparison of accuracy of remote sensing information extraction}

In order to test the accuracy of water area extraction by various index methods, this study performed artificial visual interpretation of the water boundary of three remote sensing images in 1996, 2005, and 2015, respectively, to calculate the sea area of the study area. In order to reduce the interference of human factors in visual interpretation, three visual interpretations were performed on each period of remote sensing image and averaged as the final truth value. Based on this, the relative errors of other extraction methods are calculated.The relative error calculation formula is: [(measured value-true value) / true value * 100\%]. 
As can be seen from Figures 2, 3, and 4, compared with TM4 single-band grayscale maps, the NDWI, MNDWI, and RNDWI classification maps have enhanced water information to a certain extent. Among them, the MNDWI and RNDWI classification maps have better results, which can obviously eliminate building errors. The data extracted by the MNDWI and RNDWI indices can also significantly eliminate the impact of shoals and sandy lands in the estuary, and highlight the boundary characteristics of farming land. Because buildings have the same average value of band 2 than band 4 as water bodies, the NDWI of some buildings cannot be clearly distinguished from water bodies, and even the waters of the breeding area are divided into seawater areas, which causes large errors.

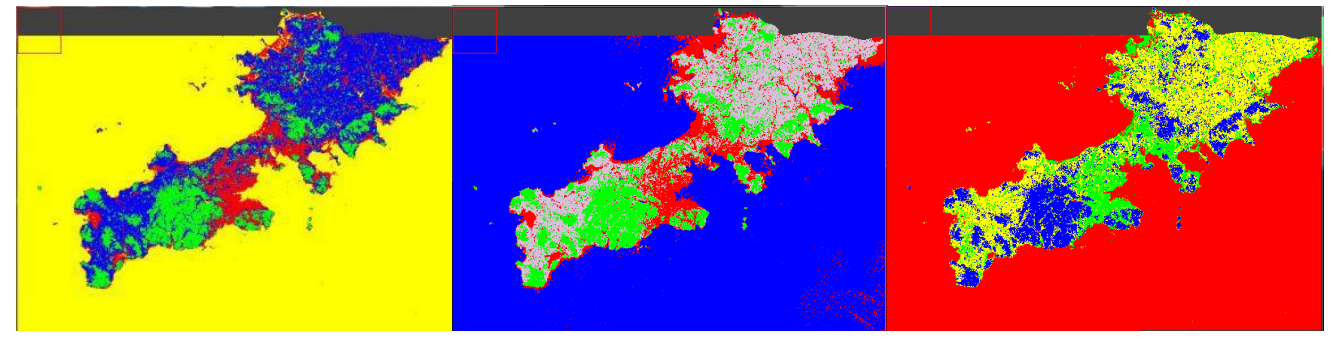

Figure 2. Classification map of NDWI, MNDWI, RNDWI thresholds in 1996.

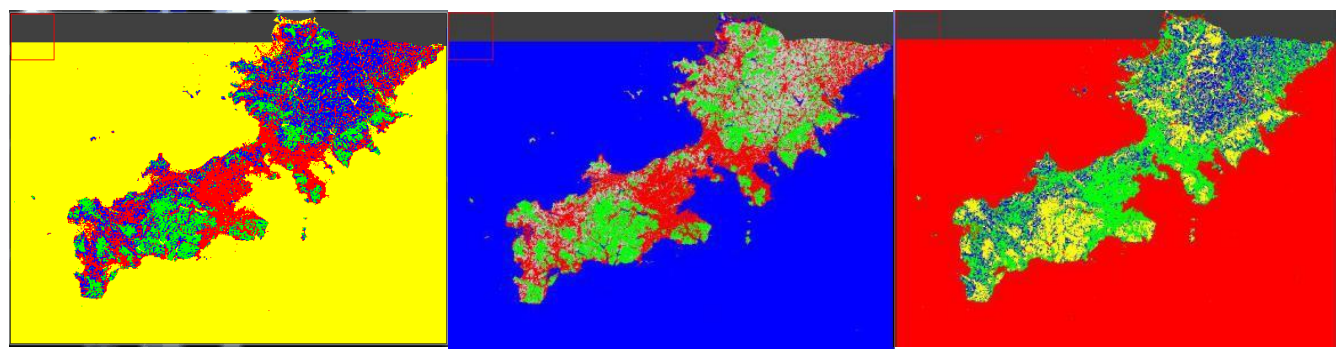

Figure 3. Classification map of NDWI, MNDWI, RNDWI thresholds in 2005.

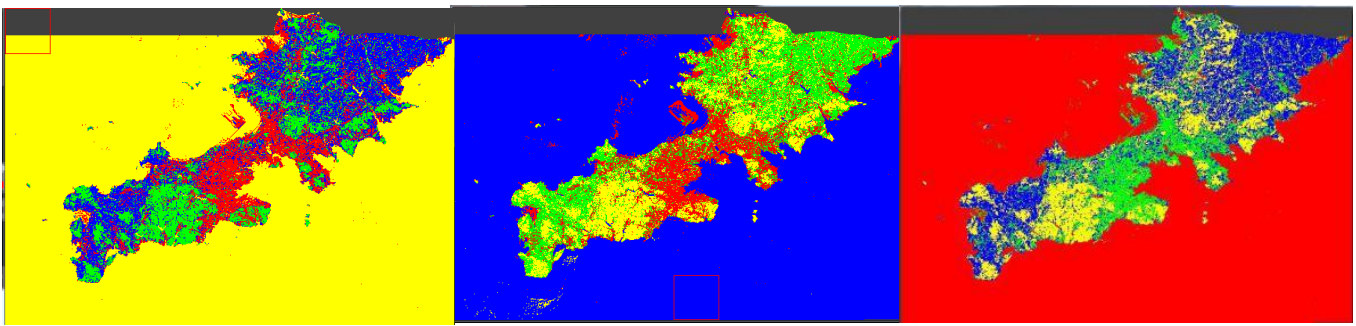

Figure 4. Classification map of NDWI, MNDWI, RNDWI thresholds in 2015.

\subsection{Analysis of reclamation process}

In this paper, the MNDWI index method is used to extract the coastline, and ArcGIS is used to extract the coastline change areas. The overlay analysis method is used to calculate that the sea area is reduced by $114.13 \mathrm{Km}$, indicating that the area of reclamation is about $114.13 \mathrm{Km}$. Among them, the reclamation area from 1996 to 2005 was about $31.58 \mathrm{Km}$, with an average annual reclamation of $3.51 \mathrm{Km}$; the reclamation area from 2005 to 2015 was about $83.55 \mathrm{Km}$. Most of the reduced sea area in the study area is located in the southeast of the study area. These areas were all natural seas or shoals in 1995. After reclamation and mariculture, they gradually developed into docks, industrial land, and breeding ponds.

\section{Impact of Reclamation}

\subsection{Changes of coastline properties}

Coastline can be divided into natural shoreline and artificial shoreline according to the cause. Natural coastline is a coastline affected by natural external forces such as waves, tides, storm surges, etc. In this study, the object of the study includes bedrock coastline and sandy coastline (Figure 5). The total length of the natural coastline is continuously decreasing, and the proportion of the bedrock coastline is decreasing year by year, from $64.5 \%$ in 1996 to $41.99 \%$ in 2015 , and the total length is reduced by $75.52 \mathrm{~km}$. The sandy shoreline has not changed much, and it keeps decreasing slowly. The proportion of artificial shoreline in the total shoreline length has been increasing. The length of artificial shoreline has increased by $212.11 \mathrm{~km}$ in 19 years. The proportion has also increased from $41.99 \%$ in 1996 to 
$56.07 \%$ in 2015 . The total length exceeds the bedrock shore. By 2015, the proportion of artificial shorelines among the three shoreline types changes the most.

\section{Changes in coastline length from 1996 to 2015}

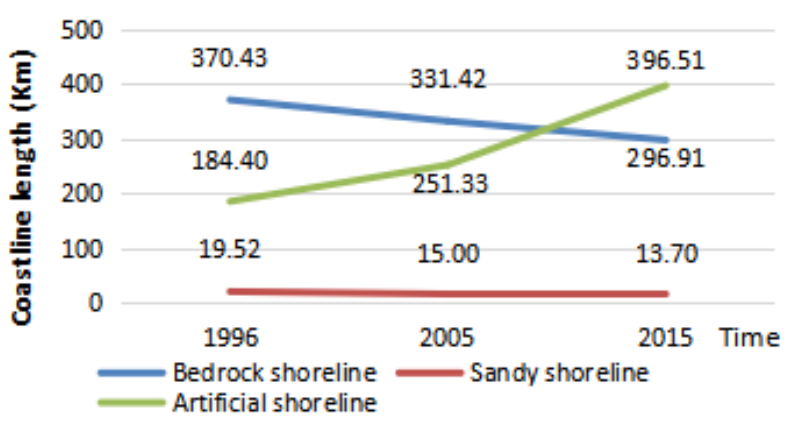

Figure 5. Line chart of coastline length change from 1996 to 2015

\subsection{Changes in land use types}

From 1996 to 2015, the area of reclaimed land was $114.13 \mathrm{~km}^{2}$, and the reclaimed land increased by an average of $8.35 \mathrm{~km}$ per year. Combined with the situation learned during the field visit, it was found that the largest proportion was the construction site, with an area of $36.02 \mathrm{~km}^{2}$, accounting for $31.56 \%$, of which $15.52 \mathrm{~km}^{2}$ was the sea airport under construction in Dalian, which is currently the largest sea airport in the world. The area of other types of land has been increasing year by year. The total area of fish ponds and breeding farms for fishery production reached $30.67 \mathrm{~km}^{2}$, accounting for $26.86 \%$ of the total reclamation area; industrial land increased from $8.28 \mathrm{~km}$ in 2005 to $16.53 \mathrm{~km}^{2}$ in 2015 ; The construction of the port terminal is still an important purpose of reclamation. From 1996 to 2015, the total reclamation area used to build the port terminal was $5.8 \mathrm{~km}^{2}$; the area of residential land increased from $0.2 \mathrm{~km}$ to $5.55 \mathrm{~km}^{2}$; There is a total of $1.95 \mathrm{~km}^{2}$ of land for building squares and urban greening. (Figure 6)

Land use types in reclamation areas

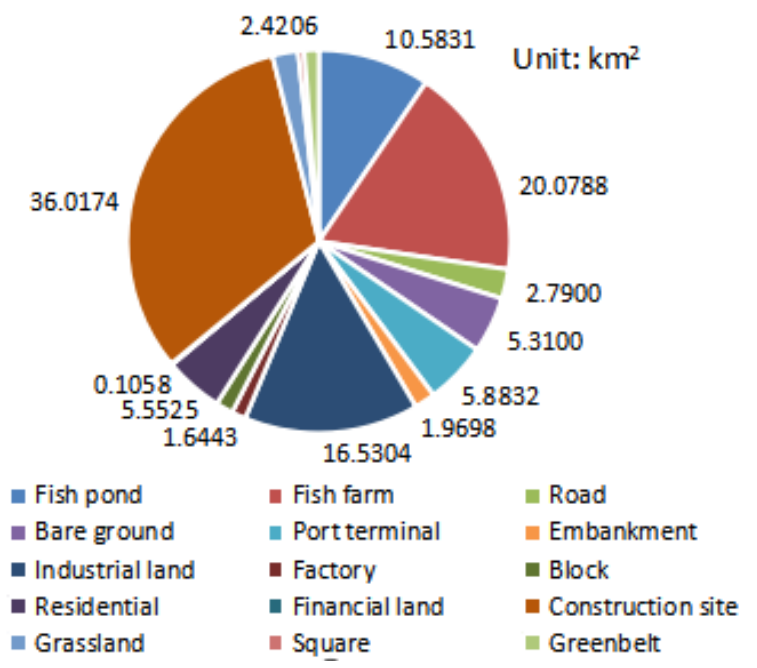

Figure 6. Land use types in reclamation areas from 1996 to 2015

\subsection{Impact of Reclamation on Marine Ecological Environment}

During the process of land reclamation, a large amount of foreign materials entered the marine environment, which greatly affected the natural properties of the sea area, and even completely destroyed the living environment unique to some organisms, leading to the reduction of marine biological diversity. A large number of biological resources have been damaged, and the ecological balance has been broken. Therefore, the above two aspects can be summarized as follows: The main impacts of land reclamation on marine biodiversity can be expressed as the decrease in the biodiversity of ordinary marine organisms and the increase in the number of specific marine species.

\subsection{Impact of Reclamation on Landform}

Under the combined influence of tidal action, wave action, biological action, and climate, natural coasts have formed a variety of unique coastal landforms, such as sea erosion arch bridges, sea erosion pillars, and sea erosion cliffs. However, due to the impact of land reclamation, the natural coastal landform features have been severely damaged, and its topographic and geomorphological effects are mainly reflected in the following aspects: First, the reclamation project directly changed the shape and length of the coastline, so that the natural evolutionary form changed to artificially constructed dams, which can reduce economic expenditures and straighten the interception of natural harbors. As a result, the length of the coastline was shortened, the form changed from broken to flat, and the form changed significantly. Secondly, in the process of land reclamation, the effect of a large amount of foreign materials has caused the offshore geomorphology to be greatly affected or even completely destroyed. Most of these damages are irreversible. Third, land reclamation has caused a large number of natural islands to disappear. At the same time, many sand dams and natural dykes have been reclaimed on a large scale to make land, and offshore islands have been turned into land. Fourth, due to the compaction of exogenous sediments and the equilibrium of the crust, the ground subsidence in the reclamation area occurred.

\subsection{Impact of Reclamation on Forest Ecological Environment}

In the image, the vegetation is magenta, and the industrial land is white. Relevant data show that the material for land reclamation in Dalian mainly comes from the surrounding mountains. This article extracts and compares the changing regions of the mountain in the 1996, 2005, and 2015 remote sensing images(Figure 7). It can be seen from the figure that from 1996 to 2015, the area of red spots in the image decreased year by year, and the area of white spots increased year by year. It can be known that in the past ten years, the phenomenon of mountain opening in Dalian has been severe, resulting in 
a reduction in the area covered by the vegetation of the mountain. The damaged mountain is mainly used for reclamation, road construction, and construction. (Figure 7)

The reduction of vegetation on the one hand reduces the amount of soil organic matter, leading to the decline of soil fertility; on the other hand, after the vegetation is destroyed, the ground surface loses its protective effect, causing soil and water loss, and may even increase the frequency of natural disasters such as mudslides. In addition, the changes in the elevation of the mountain caused by the opening of the mountains have caused the topographic changes in local areas to a certain extent, which directly exposed the rocks to the air, which will have a certain impact on the local climate in the long run.

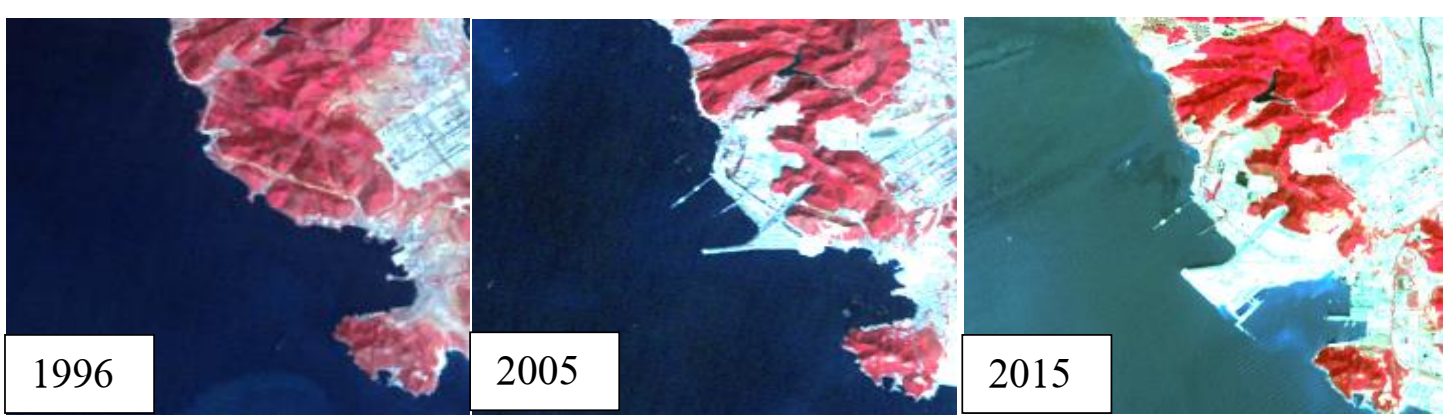

Figure 7. Mountain changes in remote sensing images from 1996 to 2015.

\section{Conclusion and prospect}

This article takes Dalian, Liaoning Province as an example, and uses remote sensing and GIS technology to explore the local coastline changes in the past ten years and its environmental impact based on the three phases of remote sensing images in 1996, 2005, and 2015. From 1996 to 2015 , the total reclamation area of Dalian was $115.03 \mathrm{~km}^{2}$, and the material originated from the surrounding mountains. The land in the reclamation area was mainly used for fisheries and aquaculture. The total length of the coastline increased by $132.77 \mathrm{~km}$, the length of the bedrock shoreline decreased year by year, and the proportion of artificial shorelines increased.Although the land reclaimed for industrial use has brought certain social benefits and promoted local economic development to some extent, the land reclaimed will have an impact on the marine ecological environment, and bare mountains may affect the forest ecological environment and climate.

\section{Acknowledgments}

This work was financially supported by Graduate Innovation Fund of Jilin University. (No.101832018C035)

\section{References}

1. S.Karan, S. Samadder, S. Maiti, Journal of environmental management, 182 (2016)

2. S. Zhao, Y. Liu, M. Li, C. Sun, M. Zhou, H. Zhang, China Ocean Engineering, 29(1) (2015)

3. M. Siddiqui, S. Maajid, Advances in Space Research, 33: 1200-1205 (2004)

4. D. Mason, T. Scotta, S. Dance, Estuarine, Coastal and Shelf Science, 88: 487-496 (2012)

5. Y. Li, P. Li, H. Pan, Marine Economy, 5(3): 41-47 (2015)

6. S, Li, C Yan, T. Wang, Environmental Earth Sciences, 78(10) (2019)

7. R. Cao, C. Li, L. Liu, Science of Surveying and Mapping, 33(2): 158-160 (2008) 